\title{
Microarray technology offers a novel tool for the diagnosis and identification of therapeutic targets for male infertility
}

\author{
Zuping He, Wai-Yee Chan and Martin Dym \\ Department of Biochemistry and Molecular and Cellular Biology, Georgetown University Medical Center, 3900 \\ Reservoir Road NW, Washington, District of Columbia 20057, USA
}

Correspondence should be addressed to M Dym; Email: dymm@georgetown.edu

\begin{abstract}
Male infertility is now a major reproductive health problem because of an increasing number of environmental pollutants and chemicals, which eventually result in gene mutations. Genetic alterations caused by environmental factors account for a significant percentage of male infertility. Microarray technology is a powerful tool capable of measuring simultaneously the expression of thousands of genes expressed in a single sample. Eventually, advances in genetic technology will allow for the diagnosis of patients with male infertility due to congenital reasons or environmental factors. Since its introduction in 1994, microarray technology has made significant advances in the identification and characterization of novel or known genes possibly correlated with male infertility in mice, as well as in humans. This provides a rational basis for the application of microarray to establishing molecular signatures for the diagnosis and gene therapy targets of male infertility. In this review, the differential gene expression patterns characterized by microarray in germ and somatic cells at different steps of development or in response to stimuli, as well as a number of novel or known genes identified to be associated with male infertility in mice and humans, are addressed. Moreover, issues pertaining to measurement reproducibility are highlighted for the application of microarray data to male infertility.

Reproduction (2006) 132 11-19
\end{abstract}

\section{Introduction}

Microarray technology, including cDNA and oligonucleotide microarrays, has the potential to measure simultaneously thousands of genes expressed in a biological sample, such as cultured cells or dissected tissues. For small samples, the targets can be expanded using RNA amplification (Guatelli et al. 1990, Van Gelder et al. 1990) or PCR-based cDNA amplification technology (Petalidis et al. 2003). This makes it possible to start with as few as 100 cells, a fine biopsy measuring $1 \mathrm{~mm} \times 1 \mathrm{~mm}$, or a minimum of $200 \mathrm{ng}$ total RNA, and obtain the labeled targets sufficient for hybridization to an array (Fox et al. 2003).

Male infertility is now a major reproductive health problem and the field has attracted considerable attention from scientists and clinicians (Skakkebaek 2003). Worldwide, infertility affects approximately $15 \%$ of couples (Nishimune \& Tanaka 2006) vs $8 \%$ in the US (Leke et al. 1993), and more importantly, in half the couples, infertility can be traced to the male (De Kretser \& Baker 1999, Nishimune \& Tanaka 2006). In some regions, for example in Africa, infertility is around $30-40 \%$ and men account for $30 \%$ of this infertility (Leke et al. 1993). What is even more disturbing is that the quality of human sperm is decreasing because of environmental pollutants and chemicals, which is believed to cause gene mutations (Duty et al. 2003, Sharpe \& Irvine 2004). Therefore, genetic disorders might account for a significant percentage of male infertility. It has been reported that $17 \%$ of patients with male infertility have abnormal genes (Aoki \& Carrell 2003, Rucker et al. 1998) and 17\% of severe male infertile patients show an abnormal content of protamine 2 in sperm (Carrell \& Liu 2001). In addition, severe oligozoospermia and azoospermia are known consequences of some microdeletions (small interstitial deletions) in the azoospermia factor regions of the $\mathrm{Y}$ chromosome or in other chromosomes (Vogt et al. 1996, Vogt 1997, Escalier 2001 ). Further, in a number of patients with male infertility, the cause is congenital (Vogt 1995, Vogt et al. 1996), but there is still a poor understanding of the genetic defects underlying this abnormality. Thus, the knowledge of the differences in gene expression between normal men and patients with male infertility is essential for understanding male-factor infertility. Microarray technology is a powerful tool for 
detecting the changes in gene expression between normal and infertile men. If the accuracy of using differences in gene expression profiles to distinguish patients with male infertility from normal men can be established, microarray technology can be utilized to provide molecular signatures for the clinical diagnosis and gene therapy of male infertility.

In this review, we focus on discussing the differentially expressed genes in male germ and somatic cells at different steps of development, or in response to stimuli, and in transgenic mice compared with normal control mice (Table 1). We also review a number of novel or known genes identified by microarray technology to be correlated with male infertility in mice and humans (Table 2), and then underscore the reproducibility in the usage of microarray technology as a tool for detecting male infertility.

\section{Differentially expressed genes characterized by microarray technology in male germ and somatic cells at different steps of development}

Microarray technology has been used to compare gene expression profiles in mitosis, meiosis, and postmeiotic steps during rodent spermatogenesis and a large number of genes have been demonstrated to be differentially expressed during these unique processes. Indeed, using the Affymetrix Genechip system containing approximately 36000 gene transcripts, Shima and colleagues delineated thousands of unique transcripts that were shown to be differentially transcribed in the mouse testis during the progression of spermatogenesis (Shima et al. 2004). This time-course analysis of testis development can be used to reveal the temporal sequence of gene activation and unlock the underlying regulatory networks and pathways required for normal spermatogenesis and male fertility. Similarly, thousands of genes were also characterized to be differentially expressed at the mitotic, meiotic, and postmeiotic steps of rat spermatogenesis (Schlecht et al. 2004). It is noteworthy that more than 290 unknown gene transcripts were identified and some of them were potentially essential for male fertility, since they displayed strong expression throughout meiotic and postmeiotic steps of spermatogenesis. In addition, a large number of gene transcripts were demonstrated to be meiotically and postmeiotically upregulated during or after mouse meiosis, and significantly, 17 out of 19 genes with targeted disruption by homologous recombination were shown to be essential for normal male fertility (Schultz et al. 2003). In one study on gene expression during mouse spermatogenesis, cell-specific geneexpression profiles, including the pachytene cluster, the spermatid cluster, and the non-germ cell cluster, were also identified and characterized by microarray analysis and other technologies (Almstrup et al. 2004a). In another study on both mice and human, more than 100 genes were shown to be differentially expressed at different stages of testis development, and 42 out of these genes were novel and may encode proteins, important for male fertility (Sha et al. 2002). We also discovered hundreds of genes that were differentially transcribed at distinctive steps of male germ cell development, i.e. type A spermatogonia, pachytene spermatocytes, and round spermatids (Pang et al. 2003). Several hundred unique unigene clusters specific in type A spermatogonia, pachytene spermatocytes, and round spermatids, were recognized, and more importantly, numerous novel gene transcripts were found to be most abundantly expressed

Table 1 Summary of studies using microarray analysis to characterize the differentially expressed genes in germ and somatic cells at different steps of development or in response to stimuli, and in transgenic mice.

\begin{tabular}{|c|c|c|c|}
\hline Species & Tissue/cell type/transgenic mice & Microarray employed & References \\
\hline Human & Adult testes vs fetal testes & cDNA microarray & Sha et al. (2002) \\
\hline \multirow[t]{10}{*}{ Mouse } & $\begin{array}{l}\text { Type A spermatogonia vs pactytene spermatocytes vs } \\
\text { spermatids }\end{array}$ & cDNA microarray & Pang et al. (2003) \\
\hline & Testes from different postnatal day and somatic cells & Oligonucleotide microarray & Schultz et al. (2003) \\
\hline & Testes from different postnatal day & cDNA microarray & Almstrup et al. $(2004 b)$ \\
\hline & FSH-treated vs untreated testes from hypogonadal mice & Oligonucleotide microarray & Sadate-Ngatchou et al. (2004a) \\
\hline & TP-treated vs untreated testes from hypogonadal mice & Oligonucleotide microarray & Sadate-Ngatchou et al. $(2004 b)$ \\
\hline & $\begin{array}{l}\text { Testes from different postnatal day, Sertoli cells, myoid cells, } \\
\text { various germ cells }\end{array}$ & Oligonucleotide microarray & Shima et al. (2004) \\
\hline & Testes from MSYq-defective vs normal control & cDNA microarray & Ellis et al. (2005) \\
\hline & $\begin{array}{l}\text { GDNF-treated type A spermatogonia vs untreated type A } \\
\text { spermatogonia }\end{array}$ & Oligonucleotide microarray & Hofmann et al. (2005) \\
\hline & Testes from MSYq-defective vs normal control & cDNA microarray & Toure et al. (2005) \\
\hline & TP or dihydrotestosterone-treated testes vs untreated testes & Oligonucleotide microarray & Zhou et al. (2005) \\
\hline \multirow[t]{4}{*}{ Rat } & FSH-treated vs untreated Sertoli cells & Oligonucleotide microarray & McLean et al. (2002) \\
\hline & $\mathrm{SG}, \mathrm{SC}, \mathrm{ST}, \mathrm{SE}$, and total testes & Oligonucleotide microarray & Schlecht et al. (2004) \\
\hline & Progeitor, immature, and adult Leydig cells & cDNA microarray & Ge et al. (2005) \\
\hline & FSH antibody vs control antibody-treated testes & Oligonucleotide microarray & Meachem et al. (2005) \\
\hline
\end{tabular}

vs, versus; FSH, follicle-stimulating hormone; TP, testosterone propionate; MSYq, the Y-chromosome long arm; GDNF, gilal cell line-derived neurotropic factor; SG, spermatogonia; SC, spermatocytes; ST, spermatids; SE, Sertoli cells. 
Table 2 Summary of novel and known genes identified by microarray analysis to be corrected with male infertility.

\begin{tabular}{|c|c|c|c|}
\hline Species & Tissue and cell types & Novel or known genes & Reference \\
\hline \multirow{7}{*}{ Human } & Adult testes vs embryo testes & tsMACK & Cheng et al. (2002) \\
\hline & Adult testes vs embryo testes & NYD-SP16 & Cheng et al. (2003) \\
\hline & Adult testes vs fetal testes & NYD-SP12 & Xu et al. (2003a) \\
\hline & Adult testes vs fetal testes vs spermatozoa & PKH-T & Fang et al. (2004) \\
\hline & Normal testes vs azoospermic testes & Rap1A & Yang et al. (2004) \\
\hline & Adult testes vs embryo testes vs sperm & BRDT-NY & Zheng et al. (2005a) \\
\hline & Adult testes vs embryo testes & BGR-like gene & Zheng et al. (2005a) \\
\hline \multirow[t]{7}{*}{ Mouse } & $\begin{array}{l}\text { Caput epididymidis of c-ros knockout mice vs } \\
\text { wild-type mice }\end{array}$ & EAAC1 & Wangenfeld et al. (2002) \\
\hline & Epididymidis of c-ros knockout mice vs wild-type mice & $\mathrm{NaP}_{\mathrm{i}}-\mathrm{Ilb}$ & Xu et al. (2003b) \\
\hline & Normal testes vs infertile testes & Itg $\alpha 6, \operatorname{Itg} \beta 1$, Maged, Rbm3, and Vim & Ellis et al. (2004) \\
\hline & Normal testes vs XXSxrb testes & Dazl and Taf7l & \\
\hline & Normal testes vs $\mathrm{Bax}^{-1-}$ testes & Aard, Akr1b3, and Def $\beta 119$ & \\
\hline & Testes from wild-type vs Dazl knockout mice & Syce1 and Cesc 1 & Maratou et al. (2004) \\
\hline & Testes from MSYq-defective vs control mice & Sly & Toure et al. (2005) \\
\hline
\end{tabular}

vs, versus; MSYq, the Y-chromosome long arm.

in these three types of germ cells (Pang et al. 2003). Additionally, a number of the proliferation-related genes were demonstrated by cDNA microarray analysis to be downregulated, while more differentiation-related genes were shown to be upregulated over the course of rat Leydig cell development, including progenitor, immature, and adult Leydig cells (Ge et al. 2005). This gene expression profiling can offer novel insights into the molecular mechanisms regulating the development of Leydig cells and other testicular functions, such as steroidogenesis. Together, these enormous resources of gene expression profiles of germ and somatic cells at different developmental steps characterized by microarray technology during spermatogenesis may be helpful to unravel the molecular mechanisms of spermatogenesis and the genetic etiology of male infertility.

\section{Differential gene expression characterized by microarray technology in male germ and somatic cells in response to stimuli}

Another application of microarray technology to spermatogenesis and male infertility is to compare gene expression profiles in germ or somatic cells with and without hormonal or growth factor treatment. There are many hundreds of genes showing differential expression patterns in the neonatal mouse testes treated with testosterone propionate (TP) for different time compared with control testes derived from 8-day-old mice (Zhou et al. 2005). However, in the testes of hypogonadal mice with TP treatment, relatively fewer genes were differentially expressed at the corresponding treatment time (Sadate-Ngatchou et al. 2004b). It is noteworthy that more genes were downregulated than upregulated in mouse testes during the short-time treatment $(<24 \mathrm{~h})$ with TP, suggestive of a role for TP in suppressing gene expression. In contrast, more genes were shown to be upregulated by follicle-stimulating hormone $(\mathrm{FSH})$ in testes of hypogonadal mice, reflecting a primary role of FSH in increasing gene expression (Sadate-Ngatchou et al. 2004a). Furthermore, hundreds of genes were shown to be differentially expressed by microarray analysis in rat Sertoli cells after FSH treatment in vitro for different time (McLean et al. 2002). The gene transcripts regulated by FSH in vivo were also identified in rats from 14 to 18 days post partum by oligonucleotide microarray, and the FSHtargeted genes may be useful to shed light on the molecular basis of pathological changes in testis, including male infertility (Meachem et al. 2005). In glial cell line-derived neurotrophic factor family receptor $\alpha-1$ (GFR $\alpha-1)$-positive type A spermatogonia, treatment with glial cell line-derived neurotropic factor (GDNF), thousands of genes were demonstrated to be differentially expressed as compared with the GDNF untreated control (Hofmann et al. 2005), and some of the genes with differential expression were related to cellular proliferation, differentiation/development, or stem cell fate. These experiments regarding the profiles of hormone and growth factor-regulated genes in the whole testis or in isolated germ or somatic cells should allow for a more thorough understanding of the influence of hormones and growth factors upon spermatogenesis, as well as on the pathogenesis of male infertility.

\section{Novel or known genes identified by microarray technology to be correlated with male infertility in mice}

The comparison of infertile and normal states, using microarray technology, allows for the rapid discovery of novel or known candidate genes affecting male fertility. In the infertile c-ros receptor tyrosine-kinase knockout mice, the expression of glutamate transporter excitatory amino acid carrier 1 (EAAC1) was shown to be completely absent (Wagenfeld et al. 2002), whereas the sodium-inorganic phosphate co-transporter $\left(\mathrm{NaP}_{\mathrm{i}}-\mathrm{Ilb}\right)$ 
was overexpressed (Xu et al. 2003 b), suggesting that the abnormal expression of EAAC1 and $\mathrm{NaP}_{\mathrm{i}}-\mathrm{Il}$ b may play potential roles in male infertility in that the c-ros gene knockout mice are sterile. In the wild-type mouse testes, synaptonemal complex central element 1 (Syce1) and central element synaptonemal complex 1 (Cesc1) were shown to be expressed at increasing levels between days 7 and 11 post partum, but it is not the case in the deleted in azoospermia (DAZ)-deficient mice (Maratou et al. 2004). SYCE1 and CESC1 protein encoded by Syce1 and Cesc 1 respectively have been demonstrated to be recruited by synaptonemal complex protein 1 (SYCP1) and play a putative role in the assembly, stabilization, and recombination of the synaptonemal complex, a key step for meiosis (Costa et al. 2005), suggesting that Syce1 and Cesc 1 play possible roles in regulating spermatogenesis and mammalian fertility.

Genetically male infertile mice were also used as models to examine the molecular signatures that distinguish pathological and normal states. Four mouse models of male infertility, including XXSxr ${ }^{b}$ male mice, mshi homozygotes, Bax ${ }^{-1-}$ male mice, and bs homozygotes, were employed to compare their abnormal gene expression profiles with normal fertile mice during the first wave of spermatogenesis using microarray analysis. The results demonstrated that integrin $\alpha 6$ (Itg $\alpha 6)$, integrin $\beta 1(\operatorname{Itg} \beta 1)$, melanoma antigen, family $\mathrm{D}$ (Maged), RNA-binding motif protein 3 (Rbm3), and vimentin (Vim) transcripts specific in Sertoli cells, were overexpressed in all four defective models (Ellis et al. 2004). On the contrary, a number of spermatogonial gene transcripts, including deleted in azoospermia-like (Dazl) and TAF7-like RNA polymerase II, TATA boxbinding protein-associated factor (TAF7l), were underexpressed in XXSxr ${ }^{b}$ males; while somatic gene transcripts, such as alanine and arginine rich domain containing protein (Aard), aldo-keto reductase family 1, member B3 (Akr1b3), and defensin, $\beta 119$ (Defß119), were overexpressed in $\mathrm{Bax}^{-1-}$ male mice. This suggests that overexpression of these somatic gene transcripts or underexpression of spermatogonial gene transcripts play potential roles in the progress of mouse male infertility. Furthermore, dozens of the Y-chromosome long arm (MSYq)-encoded transcripts were also shown to be significantly reduced in the three MSYq-deficiency mouse models, including 2/3 $\mathrm{MSYq}^{-}, 9 / 10 \mathrm{MSYq}^{-}$, and $\mathrm{MSYq}^{-}$mice (Toure et al. 2005). Among them, Sycp3-like Y-linked (Sly), encoding a putative protein homologue to the proteins XLR and XMR that are coded by $\mathrm{X}$-chromosome relatives, should be highlighted since Sly deficiency is the more likely cause of the abnormality in sperm head shape found in males with MSYq-deficiencies. These data suggest that microarray technology is an effective tool to identify novel candidate genes that contribute to male infertility. Based on a different normalization method of microarray data, Ellis and colleagues demonstrated that the majority (more than
$65 \%$ ) of the upregulated transcripts in the same three MSYq-deficiency models was from the X- or Y-linked copies (Ellis et al. 2005). The above-mentioned studies illustrate that microarray technology can be used to identify X- or Y-chromosome-encoded transcripts, and that abnormal expression (downregulation or upregulation) of these genes is likely to cause male mouse infertility. Due to a close similarity between mouse and human spermatogenesis, microarray analysis of different gene expression profiles between the mouse models of male infertility compared with normal fertile mice can shed light on the identification of novel genes important in human male infertility.

\section{Novel genes identified by microarray technology to be correlated with male infertility in humans}

Microarray technology is also being used to identify new genes that may be closely correlated with male infertility in humans. Through constructing a human adult testis cDNA microarray, Cheng and colleagues identified a novel testis-specific gene tsMCAK, homologue to gene HsMCAK, encoding human testis-specific mitotic centromere-associated kinesin (Cheng et al. 2002). tsMCAK was expressed in the testes of patients with spermatogenic arrest at the spermatocyte step, but it was absent in the testes of infertility patients with Sertoli-cell-only syndrome or in the testes of infertility patients with spermatogenic arrest occurring in spermatids, indicating that tsMCAK may be involved in the later steps of spermatogenesis and that lost expression of tsMCAK may be correlated with male infertility. Subsequently, they identified another novel human testicular gene called NYD-SP16, which encodes probably the spermatogenesis-associated nine protein (Cheng et al. 2003). It is notable that NYD-SP16 was absent in the testes of infertile patients with Sertoli-cellonly syndrome (Cheng et al. 2003). Likewise, Xu and colleagues characterized a new spermatogenesisrelated gene, NYD-SP12, which encodes a testisspecific Golgi protein (Xu et al. 2003a). NYD-SP12 was primarily expressed in spermatocytes and spermatogonia, but not in somatic cells in mice at different ages, and more importantly, NYD-SP12 transcript was not detected in all the patients with spermatogenic arrest or Sertoli-cell-only syndrome. Further, a novel pyridoxal kinase mRNA splice variant, PKH-T, was shown to be highly expressed in adult human testis and spermatozoa, but was absent in the testis of patients with Sertoli-cell-only syndrome and in some patients with spermatogenic arrest (Fang et al. 2004). In short, the abnormal expression of these genes mentioned above in infertile men or patients with spermatogenic arrest may be correlated with male infertility. In 2005, two new genes, including bubblegum-related-like (BGR-like) and BRDT-NY genes, an alternative splice 
variant of BRDT gene (bromodomain, testis-specific), were also identified and characterized through microarray analysis (Zheng et al. 2005a, 2005b). Gene BGR encodes bubblegum-related protein and gene BRDT codes testis-specific bromodomain protein. Intriguingly, neither BRDT-NY nor BGR-like gene transcript was detected in the testis of certain azoospermic patients, suggestive of potential roles of both genes in the development of azoospermia. In addition, hundreds of genes were differentially expressed in the testes between fertile and azoospermic patients (Yang et al. 2004); among these genes, the mRNA expression of RAS-related protein-1A (Rap1A), a member of the RAS oncogene family, was higher in the azoospermic testes compared with the normal testes, suggesting that Rap1A might play a role in the process of azoospermia. Taken together, these studies demonstrate that microarray technology is feasible for the identification of male infertility-related candidate genes that are likely to provide molecular signatures for the diagnosis and gene therapy for male infertility in the future. Aberrant expression of these novel genes may result in male infertility, and thus exploration of these specific genes could also account for the pathological mechanisms of male infertility (Okabe et al. 1998). An important caveat is that the data obtained from human samples so far show no direct comparison between normal men and patients, since they do not have well-characterized genetic differences, while it is the case, for example, with mouse Y-chromosome depletion models (Ellis et al. 2005, Toure et al. 2005).

On the other hand, microarray analysis was used to address other aspects of human testicular dysgenesis syndrome, such as testicular carcinoma in situ (CIS). One of the largest microarrays was employed to identify several hundred gene transcripts that were upregulated in testicular tissue from CIS as compared with normal testicular parenchyma (Almstrup et al. 2004b). These microarray data are likely to offer novel candidates for diagnostic markers for CIS and account for the pluripotency of $\mathrm{CIS}$, since a range of embryonic stem cell markers, including NANOG, a homeobox transcription factor, and POU5F1, an octamer-binding transcription factor, is highly expressed in CIS. Meanwhile, microarray analysis was also employed to characterize expression changes of numerous novel genes and oncogenes in testicular germ cell tumors (TGCT) and testicular seminomas (Skotheim et al. 2002, Yamada et al. 2004), and this should be helpful to identify new treatment targets for TGCT and seminoma and also shed light on the tumorigenesis of these conditions.

\section{Reproducibility is essential for the application of microarray data to male infertility}

Microarray analysis comprises a multi-step process. The basic procedure of oligonucleotide microarray, for example, involves the extraction and purification of total RNA or mRNA from normal and abnormal samples, the synthesis and cleanup of double-strand CDNA and biotin-labeled cRNA that is subsequently fragmented for the targets. The fragmented cRNA is then hybridized to a Genechip containing tens and thousands of cDNAs or oligonucleotides, after which the excess is washed off and the microarray can be scanned under a laser light for the signal of individual probes. The raw data are acquired and analyzed using appropriate software. Each step contributes to the quality of the data in the microarray analysis. Certain significant issues associated with microarray analysis, including experiment design, target preparation, array hybridization, data analysis and validation, have been described in detail elsewhere (White \& Salamonsen 2005).

It is worth considering four major characteristics, namely the absolute expression levels, the subtractive degree of change, the fold changes, and the reproducibility of the data when comparing the gene expression profile between two samples using microarray technology (Butte 2002). Among these aspects, reproducibility is of paramount importance. One way to show the reproducibility of microarray analysis is to repeat the experiments at least two or three times. Wodicka and colleagues have reported that $99.8 \%$ of genes have a similar expression pattern when a sample is hybridized to two identical arrays, and $99 \%$ similarity can be obtained when independent samples are employed (Wodicka et al. 1997). In order to confirm the reproducibility of microarray technology, we compared the gene expression profiles of the seminiferous tubules derived from adult mice using oligonucleotide microarray. We made two independent preparations of RNA targets and used $15 \mu \mathrm{g}$ biotin-labeled cRNA for hybridization with the mouse Genechips containing 12488 gene transcripts. Microarray analysis revealed that 6729 gene transcripts were present in both seminiferous tubule preparations, and only 17 out of 6729 transcripts were differentially expressed between these two samples (Fig. 1), indicating that $99.72 \%$ of transcripts have a very similar expression profile. Significantly, a high reproducibility for the mouse expression profile of differentially regulated genes was also acquired in two different laboratories (Schultz et al. 2003, Shima et al. 2004), and the oligonucleotide microarray data are highly reproducible in similar genes between different species, such as mice and rats (Schultz et al. 2003, Shima et al. 2004, Wrobel \& Primig 2005).

Another way to test the reproducibility of microarray data is to confirm the mRNA expression of differentially expressed genes of particular interest by existing molecular technologies, such as real-time reverse transcriptase (RT) and PCR (real-time RT-PCR), semi-quantitative RT-PCR, differential display competitive PCR, northern blots, and RNA in situ hybridization. Ellis et al. identified hundreds of transcripts that were differentially 


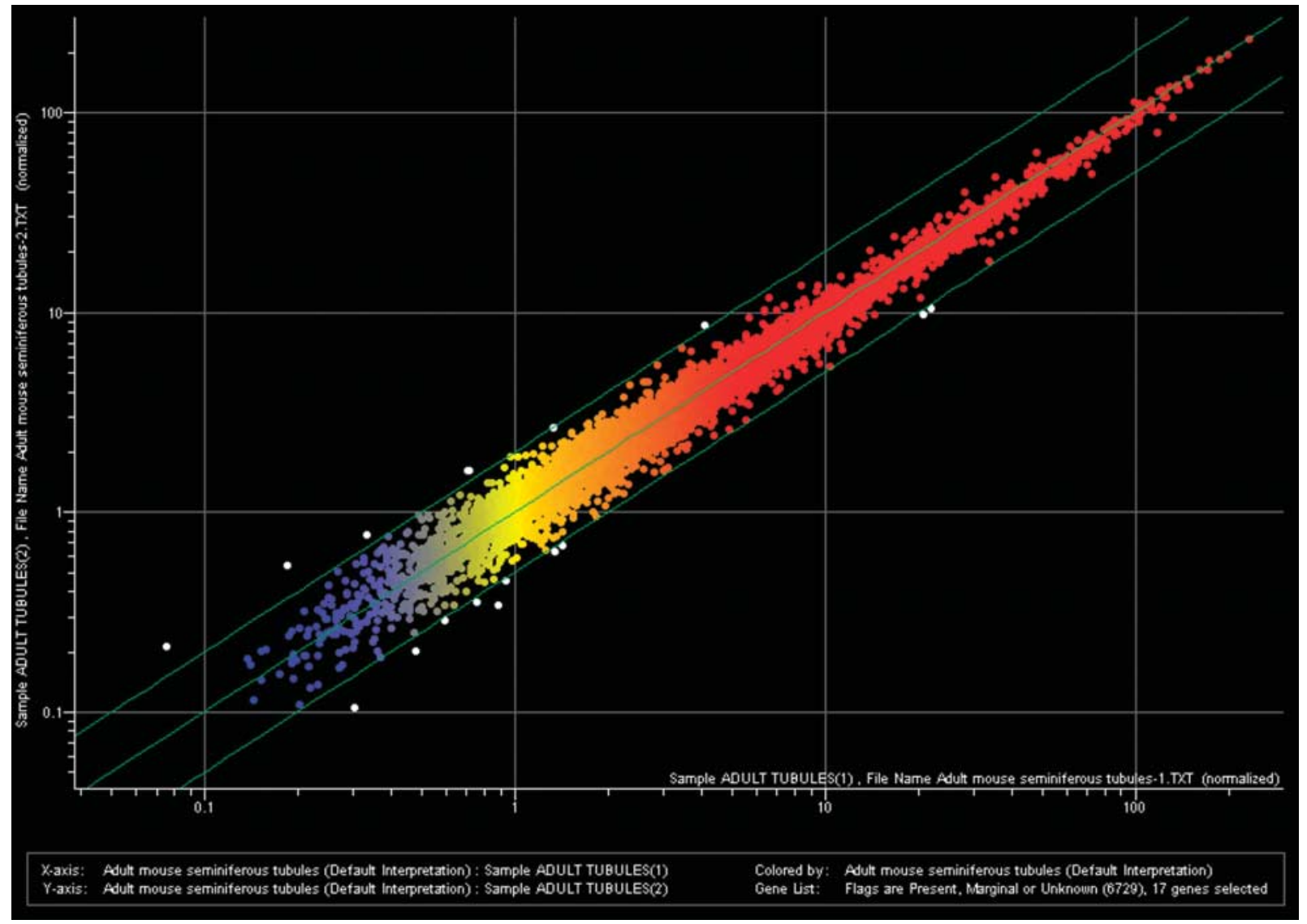

Figure 1 Scatter plot comparison of gene expression pattern in two samples of adult mouse seminiferous tubules. Each dot represents a specific gene expression present in adult mouse seminiferous tubules. Gene transcripts that were upregulated or downregulated more than two-fold were considered to be differentially expressed. Gene transcripts with no change were represented along the center green line. Gene transcripts that were upregulated more than two-fold were shown above the upper green line, and gene transcripts that were downregulated more than two-fold were shown below the lower green line. There were only 17 transcripts that were shown to be differentially expressed between two independent samples as highlighted by the white dots.

expressed during the first wave of mouse spermatogenesis, and they obtained the confidence of data quality by real-time RT-PCR (Ellis et al. 2004). They also verified the upregulated gene transcripts in MSYq-deficient mice by northern blotting and underpinned the reproducibility of the microarray data in sex chromosome-linked genes using real-time RT-PCR (Ellis et al. 2005). Almstrup and colleagues combined a number of methodologies, including microarray, differential display competitive PCR, and in situ hybridization, to identify three groups of cell-type-specific gene-expression profiles during spermatogenesis (Almstrup et al. 2004a). RNA in situ hybridization was also employed to confirm the microarray data showing that Sly transcript was predominantly expressed in spermatids (Toure et al. 2005). In our laboratory, we corroborated the microarray data showing col1a1 and col1a2 mRNA expression levels in the seminiferous tubules of immature and adult mice using semi-quantitative RT-PCR (He et al. 2005). Adachi and colleagues revealed that 11 genes were upregulated and three genes were downregulated by diethylstilbestrol in 28-day-old mice using cDNA microarray analysis, however, they only confirmed eight out of 11 upregulated genes by real-time RT-PCR (Adachi et al. 2002). Considered together, these examples illustrate that microarray technology is reliable and robust (Wrobel \& Primig 2005), but great attention must be paid to reproducibility when microarray technology is used as a tool to identify and characterize novel genes that are possibly correlated with male infertility. Furthermore, since mRNA expression profiles using microarray analysis of two samples cannot reveal translational controls and are unable to completely correlate with protein expression, microarray technology must be integrated with other molecular technologies, including Western blots, flow cytometric analysis, ELISA, and protein arrays.

When the sample size is very small, the RNA must be amplified using linear or exponential amplification methods, including T7-based linear RNA amplification, switching mechanism at the $5^{\prime}$-end of RNA template (SMART) PCR amplification, and global PCR 
amplification, to obtain sufficient targets for microarray analysis. On one hand, T7-based linear RNA amplification generated high fidelity microarray data compared with non-amplified mRNA samples (Zhao et al. 2002) and SMART PCR and global PCR amplification also produced reproducible results (Livesey 2003, Subkhankulova \& Livesey 2006). For example, 94\% overlap of the differentially expressed genes between the amplified samples and the unamplified ones was obtainable using linear amplification (Polacek et al. 2003). On the other hand, all three amplification methods induced errors in the microarray data (Subkhankulova \& Livesey 2006). SMART PCR amplification led to a systematic reduction in the gene-expression ratios compared with the data from the unamplified samples (Livesey 2003, Petalidis et al. 2003, Subkhankulova \& Livesey 2006), while T7based linear RNA amplification enhanced the number of differentially expressed genes when compared to the number identified from the unamplified RNA samples (Patel et al. 2005). The error of microarray data following amplification depends on many factors, including the amplification protocol (Puskas et al. 2002, Jenson et al. 2003, Petalidis et al. 2003, Wilson et al. 2004), the degree of amplification required (Zhao et al. 2002), the quality of the starting total RNA template, the concentration of the promoter primer used to synthesize cDNA (Jenson et al. 2003), and the time-dependent RNA degradation during T7-based linear RNA amplification (Spiess et al. 2003). It is noteworthy that the different amplification protocols resulted in distinct correlations between the amplified targets compared with the unamplified ones (Puskas et al. 2002, Petalidis et al. 2003). Thus, considerable attention should be paid to the systematic error of microarray data following linear or exponential amplification, and validation studies using the existing molecular methods mentioned above will reduce amplification bias.

\section{Conclusions}

Microarray technology allows for rapid access to a more precise diagnosis and better therapeutic strategies of various diseases. The Food and Drug Administration of the United States of America has a growing interest in the use of microarray technology as a diagnostic device. This offers a good opportunity for both scientists and clinicians to improve diagnostics and develop novel approaches of treatment for various male infertility diseases. Thus far, a growing number of novel or known genes have been identified and characterized by microarray technology to be possibly correlated with male infertility in mice and humans, which could reveal novel candidates for both diagnosis and therapy. However, reproducibility of microarray data is essential. If these novel genes in the molecular signature can tell us something about the pathogenesis of male infertility, microarray technology may be used as a clinical diagnostic tool and eventually lead to gene therapy.

\section{Acknowledgements}

This work was supported by National Institutes of Health Grant HD 33728 to Dr Dym. The authors declare that there is no conflict of interest that would prejudice the impartiality of this scientific work.

\section{References}

Adachi T, Komiyama M, Ono Y, Koh KB, Sakurai K, Shibayama T, Kato M, Yoshikawa T, Seki N, Iguchi T et al. 2002 Toxicogenomic effects of neonatal exposure to diethylstilbestrol on mouse testicular gene expression in the long term: a study using cDNA microarray analysis. Molecular Reproduction and Development 63 17-23.

Almstrup K, Nielsen JE, Hansen MA, Tanaka M, Skakkebaek NE \& Leffers H 2004a Analysis of cell-type-specific gene expression during mouse spermatogenesis. Biology of Reproduction $\mathbf{7 0}$ 1751-1761.

Almstrup K, Hoei-Hansen CE, Wirkner U, Blake J, Schwager C, Ansorge W, Nielsen JE, Skakkebaek NE, Rajpert-De Meyts E \& Leffers H 2004b Embryonic stem cell-like features of testicular carcinoma in situ revealed by genome-wide gene expression profiling. Cancer Research 64 4736-4743.

Aoki VW \& Carrell DT 2003 Human protamines and the developing spermatid: their structure, function, expression and relationship with male infertility. Asian Journal of Andrology 5 315-324.

Butte A 2002 The use and analysis of microarray data. Nature Reviews. Drug Discovery 1 951-960.

Carrell DT \& Liu L 2001 Altered protamine 2 expression is uncommon in donors of known fertility, but common among men with poor fertilizing capacity, and may reflect other abnormalities of spermiogenesis. Journal of Andrology 22 604-610.

Cheng LJ, Zhou ZM, Li JM, Zhu H, Zhu H, Zhou YD, Wang LR, Lin M \& Sha JH 2002 Expression of a novel HsMCAK mRNA splice variant, tsMCAK gene, in human testis. Life Sciences 71 2741-2757.

Cheng LJ, Li JM, Chen J, Ge YH, Yu ZR, Han DS, Zhou ZM \& Sha JH 2003 NYD-SP16, a novel gene associated with spermatogenesis of human testis. Biology of Reproduction 68 190-198.

Costa Y, Speed R, Ollinger R, Alsheimer M, Semple CA, Gautier P, Maratou K, Novak I, Hoog C, Benavente R et al. 2005 Two novel proteins recruited by synaptonemal complex protein 1 (SYCP1) are at the centre of meiosis. Journal of Cell Science 118 2755-2762.

De Kretser DM \& Baker HW 1999 Infertility in men: recent advances and continuing controversies. Journal of Clinical Endocrinology and Metabolism 84 3443-3450.

Duty SM, Silva MJ, Barr DB, Brock JW, Ryan L, Chen Z, Herrick RF, Christiani DC \& Hauser R 2003 Phthalate exposure and human semen parameters. Epidemiology 14 269-277.

Ellis PJ, Furlong RA, Wilson A, Morris S, Carter D, Oliver G, Print C, Burgoyne PS, Loveland KL \& Affara NA 2004 Modulation of the mouse testis transcriptome during postnatal development and in selected models of male infertility. Molecular Human Reproduction 10 271-281.

Ellis PJ, Clemente EJ, Ball P, Toure A, Ferguson L, Turner JM, Loveland KL, Affara NA \& Burgoyne PS 2005 Deletions on mouse Yq lead to upregulation of multiple $\mathrm{X}$ - and Y-linked transcripts in spermatids. Human Molecular Genetics 14 2705-2715.

Escalier D 2001 Impact of genetic engineering on the understanding of spermatogenesis. Human Reproduction Update 7 191-210.

Fang X, Zhou ZM, Lu L, Yin LL, Li JM, Zhen Y, Wang H \& Sha JH 2004 Expression of a novel pyridoxal kinase mRNA splice variant, PKH-T, in human testis. Asian Journal of Andrology 6 83-91.

Fox MS, Ares VX, Turek PJ, Haqq C \& Reijo Pera RA 2003 Feasibility of global gene expression analysis in testicular biopsies from infertile men. Molecular Reproduction and Development 66 403-421. 
Ge RS, Dong Q, Sottas CM, Chen H, Zirkin BR \& Hardy MP 2005 Gene expression in rat leydig cells during development from the progenitor to adult stage: a cluster analysis. Biology of Reproduction 72 1405-1415.

Guatelli JC, Whitfield KM, Kwoh DY, Barringer KJ, Richman DD \& Gingeras TR 1990 Isothermal, in vitro amplification of nucleic acids by a multienzyme reaction modeled after retroviral replication. PNAS 877797.

He Z, Feng L, Zhang X, Geng Y, Parodi DA, Suarez-Quian C \& Dym M 2005 Expression of Col1a1, Col1a2 and procollagen I in germ cells of immature and adult mouse testis. Reproduction $130333-341$.

Hofmann MC, Braydich-Stolle L \& Dym M 2005 Isolation of male germ-line stem cells; influence of GDNF. Developmental Biology 279 114-124.

Jenson SD, Robetorye RS, Bohling SD, Schumacher JA, Morgan JW, Lim MS \& Elenitoba-Johnson KS 2003 Validation of cDNA microarray gene expression data obtained from linearly amplified RNA. Molecular Pathology 56 307-312.

Leke RJ, Oduma JA, Bassol-Mayagoitia S, Bacha AM \& Grigor KM 1993 Regional and geographical variations in infertility: effects of environmental, cultural, and socioeconomic factors. Environmental Health Perspectives 101 (Supplement 2) 73-80.

Livesey FJ 2003 Strategies for microarray analysis of limiting amounts of RNA. Breifings in Functional Genomics \& Proteomics 2 31-36.

Maratou K, Forster T, Costa Y, Taggart M, Speed RM, Ireland J, Teague P, Roy D \& Cooke HJ 2004 Expression profiling of the developing testis in wild-type and Dazl knockout mice. Molecular Reproduction and Development 67 26-54.

McLean DJ, Friel PJ, Pouchnik D \& Griswold MD 2002 Oligonucleotide microarray analysis of gene expression in follicle-stimulating hormone-treated rat Sertoli cells. Molecular Endocrinology $\mathbf{1 6}$ 2780-2792.

Meachem SJ, Ruwanpura SM, Ziolkowski J, Ague JM, Skinner MK \& Loveland KL 2005 Developmentally distinct in vivo effects of FSH on proliferation and apoptosis during testis maturation. Journal of Endocrinology 186 429-446.

Nishimune Y \& Tanaka H 2006 Infertility caused by polymorphisms or mutations in spermatogenesis-specific genes. Journal of Andrology 27 326-334.

Okabe M, Ikawa M \& Ashkenas J 1998 Male infertility and the genetics of spermatogenesis. American Journal of Human Genetics 62 1274-1281.

Pang AL, Taylor HC, Johnson W, Alexander S, Chen Y, Su YA, Li X, Ravindranath N, Dym M, Rennert OM et al. 2003 Identification of differentially expressed genes in mouse spermatogenesis. Journal of Andrology 24 899-911.

Patel OV, Suchyta SP, Sipkovsky SS, Yao J, Ireland J, Coussens PM \& Smith GW 2005 Validation and application of a high fidelity mRNA linear amplification procedure for profiling gene expression. Veterinary Immunology and Immunopathology 105 331-342.

Petalidis L, Bhattacharyya S, Morris GA, Collins VP, Freeman TC \& Lyons PA 2003 Global amplification of mRNA by template-switching PCR: linearity and application to microarray analysis. Nucleic Acids Research 31 e142.

Polacek DC, Passerini AG, Shi C, Francesco NM, Manduchi E, Grant GR, Powell S, Bischof H, Winkler H, Stoeckert CJ Jr et al. 2003 Fidelity and enhanced sensitivity of differential transcription profiles following linear amplification of nanogram amounts of endothelial mRNA. Physiological Genomics 13 147-156.

Puskas LG, Zvara A, Hackler L Jr \& Van Hummelen P 2002 RNA amplification results in reproducible microarray data with slight ratio bias. Biotechniques 32 1330-1340.

Rucker GB, Mielnik A, King P, Goldstein M \& Schlegel PN 1998 Preoperative screening for genetic abnormalities in men with nonobstructive azoospermia before testicular sperm extraction. Journal of Urology 160 2068-2071.

Sadate-Ngatchou PI, Pouchnik DJ \& Griswold MD 2004a Folliclestimulating hormone induced changes in gene expression of murine testis. Molecular Endocrinology 18 2805-2816.
Sadate-Ngatchou PI, Pouchnik DJ \& Griswold MD 2004b Identification of testosterone-regulated genes in testes of hypogonadal mice using oligonucleotide microarray. Molecular Endocrinology 18 422-433.

Schlecht U, Demougin P, Koch R, Hermida L, Wiederkehr C, Descombes P, Pineau C, Jegou B \& Primig M 2004 Expression profiling of mammalian male meiosis and gametogenesis identifies novel candidate genes for roles in the regulation of fertility. Molecular Biology of the Cell 15 1031-1043.

Schultz N, Hamra FK \& Garbers DL 2003 A multitude of genes expressed solely in meiotic or postmeiotic spermatogenic cells offers a myriad of contraceptive targets. PNAS $\mathbf{1 0 0} 12201-$ 12206.

Sha J, Zhou Z, Li J, Yin L, Yang H, Hu G, Luo M, Chan HC \& Zhou K 2002 Identification of testis development and spermatogenesisrelated genes in human and mouse testes using cDNA arrays. Molecular Human Reproduction 8 511-517.

Sharpe RM \& Irvine DS 2004 How strong is the evidence of a link between environmental chemicals and adverse effects on human reproductive health? British Medical Journal 328 447-451.

Shima JE, McLean DJ, McCarrey JR \& Griswold MD 2004 The murine testicular transcriptome: characterizing gene expression in the testis during the progression of spermatogenesis. Biology of Reproduction 71 319-330.

Skakkebaek NE 2003 Testicular dysgenesis syndrome. Hormone Research 60 (Supplement 3) 49

Skotheim RI, Monni O, Mousses S, Fossa SD, Kallioniemi OP, Lothe RA \& Kallioniemi A 2002 New insights into testicular germ cell tumorigenesis from gene expression profiling. Cancer Research $\mathbf{6 2}$ 2359-2364.

Spiess AN, Mueller N \& Ivell R 2003 Amplified RNA degradation in T7amplification methods results in biased microarray hybridizations. BMC Genomics 444.

Subkhankulova T \& Livesey FJ 2006 Comparative evaluation of linear and exponential amplification techniques for expression profiling at the single cell level. Genome Biology 7 R18.

Toure A, Clemente EJ, Ellis P, Mahadevaiah SK, Ojarikre OA, Ball PA, Reynard L, Loveland KL, Burgoyne PS \& Affara NA 2005 Identification of novel $Y$ chromosome encoded transcripts by testis transcriptome analysis of mice with deletions of the $Y$ chromosome long arm. Genome Biology 6 R102.

Van Gelder RN, von Zastrow ME, Yool A, Dement WC, Barchas JD \& Eberwine JH 1990 Amplified RNA synthesized from limited quantities of heterogeneous cDNA. PNAS 87 1663-1667.

Vogt PH 1995 Genetic aspects of human infertility. International Journal of Andrology 18 (Supplement 2) 3-6.

Vogt PH 1997 Human Y chromosome deletions in Yq11 and male fertility. Advances in Experimental Medicine and Biology 424 17-30.

Vogt PH, Edelmann A, Kirsch S, Henegariu O, Hirschmann P, Kiesewetter F, Kohn FM, Schill WB, Farah S, Ramos C et al. 1996 Human $Y$ chromosome azoospermia factors (AZF) mapped to different subregions in Yq11. Human Molecular Genetics 5 933943.

Wagenfeld A, Yeung CH, Lehnert W, Nieschlag E \& Cooper TG 2002 Lack of glutamate transporter EAAC1 in the epididymis of infertile c-ros receptor tyrosine-kinase deficient mice. Journal of Andrology 23 772-782.

White CA \& Salamonsen LA 2005 A guide to issues in microarray analysis: application to endometrial biology. Reproduction 130 1-13.

Wilson CL, Pepper SD, Hey Y \& Miller CJ 2004 Amplification protocols introduce systematic but reproducible errors into gene expression studies. Biotechniques 36 498-506.

Wodicka L, Dong H, Mittmann M, Ho MH \& Lockhart DJ 1997 Genome-wide expression monitoring in Saccharomyces cerevisiae. Nature Biotechnology 15 1359-1367.

Wrobel G \& Primig M 2005 Mammalian male germ cells are fertile ground for expression profiling of sexual reproduction. Reproduction $1291-7$ 
Xu M, Xiao J, Chen J, Li J, Yin L, Zhu H, Zhou Z \& Sha J 2003a Identification and characterization of a novel human testis-specific Golgi protein, NYD-SP12. Molecular Human Reproduction 9 9-17.

Xu Y, Yeung CH, Setiawan I, Avram C, Biber J, Wagenfeld A, Lang F \& Cooper TG 2003b Sodium-inorganic phosphate cotransporter $\mathrm{NaPi}-\mathrm{Ilb}$ in the epididymis and its potential role in male fertility studied in a transgenic mouse model. Biology of Reproduction 69 1135-1141.

Yamada S, Kohu K, Ishii T, Ishidoya S, Hiramatsu M, Kanto S, Fukuzaki A, Adachi Y, Endoh M, Moriya T et al. 2004 Gene expression profiling identifies a set of transcripts that are up-regulated inhuman testicular seminoma. DNA Research 11 335-344.

Yang B, Wang H, Gao XK, Chen BQ, Zhang YQ, Liu HL, Wang Y, Qin WJ, Qin RL, Shao GX et al. 2004 Expression and significance of Rap1A in testes of azoospermic subjects. Asian Journal of Andrology 6 35-40.

Zhao H, Hastie T, Whitfield ML, Borresen-Dale AL \& Jeffrey SS 2002 Optimization and evaluation of T7 based RNA linea amplification protocols for cDNA microarray analysis. $B M C$ Genomics 331.
Zheng Y, Yuan W, Zhou Z, Xu M \& Sha JH 2005a Molecular cloning and expression of a novel alternative splice variant of BRDT gene. International Journal of Molecular Medicine 15 315-321.

Zheng Y, Zhou ZM, Min X, Li JM \& Sha JH 2005b Identification and characterization of the BGR-like gene with a potential role in human testicular development/spermatogenesis. Asian Journal of Andrology $721-32$.

Zhou Q, Shima JE, Nie R, Friel PJ \& Griswold MD 2005 Androgen-regulated transcripts in the neonatal mouse testis as determined through microarray analysis. Biology of Reproduction 72 1010-1019.

Received 12 December 2005

First decision 13 February 2006

Revised manuscript received 4 March 2006

Accepted 11 May 2006 